Ciência Florestal, Santa Maria, v. 23, n. 2, p. 403-414, abr.-jun., 2013

ISSN 0103-9954

\title{
ÓLEO ESSENCIAL DE EUCALIPTO COMO BIOESTIMULADOR DO CRESCIMENTO DE FUNGOS ECTOMICORRÍZICOS IN VITRO
}

\author{
EUCALYPTUS ESSENTIAL OIL AS BIO-STIMULATOR OF THE GROWTH OF IN VITRO \\ ECTOMYCORRHIZAL FUNGI
}

\author{
Ricardo Bemfica Steffen ${ }^{1}$ Zaida Inês Antoniolli ${ }^{2}$ Gerusa Pauli Kist Steffen ${ }^{3}$ \\ Rodrigo Josemar Seminoti Jacques ${ }^{4}$ Marcos Leandro dos Santos ${ }^{5}$ Helena Teixeira Godoy ${ }^{6}$ \\ Stanislau Bogusz Júnior ${ }^{7}$
}

\begin{abstract}
RESUMO
Os metabólitos secundários extraídos de essências florestais conhecidamente micossimbiontes podem estimular o crescimento de isolados ectomicorrízicos in vitro. Assim, determinou-se o efeito de concentrações do óleo essencial de Eucalyptus grandis no estímulo ao crescimento dos fungos ectomicorrízicos Pisolithus sp. (UFSC Pt 24 e UFSC Pt 188), Pisolithus microcarpus (UFSC Pt 116), Chondrogaster angustiporus (UFSC Ch 163), Scleroderma citrinum (UFSC Sc 124) e Suillus sp. (UFSM RA 2.2 e UFSM RA 2.8) em meio de cultura líquido. Após o período de 25 dias de incubação, avaliou-se a morfologia e o crescimento dos isolados. A adição do óleo essencial nas concentrações de 20 a $30 \mu \mathrm{L} \mathrm{L}^{-1}$ promoveu crescimento miceliano in vitro nos isolados UFSC Pt 24, UFSC Pt 116, UFSC Ch 163, UFSC Sc 124, UFSM RA 2.2 e UFSM RA 2.8. A adição do óleo essencial na concentração de $20 \mu \mathrm{L} \mathrm{L}^{-1}$ resultou em aumento no diâmetro e na ramificação das hifas dos isolados UFSC Pt 116 e UFSC Pt 24. A utilização de óleo essencial na elaboração de meios de cultura para o crescimento de isolados ectomicorrízicos mostra-se eficiente, por aumentar a produção de massa micelial do fungo.
\end{abstract}

Palavras-chave: crescimento miceliano; metabólitos secundários; produção de inóculo.

\section{ABSTRACT}

The secondary metabolites extracted from forest species known as micossimbiontes can stimulate the growth of in vitro ectomycorrhizal isolates. We determined the effect of concentration of Eucalyptus grandis essential oil in stimulating growth of the ectomycorrhizal Pisolithus sp. (UFSC Pt 24 and UFSC Pt 188), Pisolithus microcarpus (UFSC Pt 116) Chondrogaster angustiporus (UFSC Ch 163), Scleroderma citrinum (UFSC Sc 124) and Suillus sp. (UFSM RA RA UFSM 2.2 and 2.8) in liquid culture medium. After a period of 25 days of incubation, we evaluated the morphology and growth of the isolates. The addition of essential oil at concentrations from 20 to $30 \mu \mathrm{L} \mathrm{L}^{-1}$ promoted mycelial growth in vitro in isolated Pt $24 \mathrm{UFSC}$, UFSC Pt 116, Ch 163 UFSC, UFSC Sc 124, UFSM RA RA UFSM 2.2 and 2.8. The addition of essential oil at a concentration of $20 \mu \mathrm{L} \mathrm{L}^{-1}$ resulted in an increase in the diameter and branching hyphae of isolates UFSC Pt 116 and Pt 24 UFSC. The use of essential oil in the preparation of culture media for the growth of

1. Engenheiro Agrônomo, Dr., Pós-Doutorando no PPG Ciência do Solo, Universidade Federal de Santa Maria, Av. Roraima, 1000, CEP 97105-900, Santa Maria (RS). Bolsista CNPq. bemfica_steffen@yahoo.com.br

2. Bióloga, Dra ${ }^{\text {., }}$ Professora do Departamento de Solos, Universidade Federal de Santa Maria, Av. Roraima, 1000, CEP 97105-900, Santa Maria (RS). Bolsista CNPq. zantoniolli@gmail.com

3. Engenheira Agrônoma, Dr ${ }^{\mathrm{a}}$., Universidade Federal de Santa Maria, Av. Roraima, 1000, CEP 97105-900, Santa Maria (RS). Bolsista CNPq. ge.pauli@yahoo.com.br

4. Engenheiro Agrônomo, Dr., Professor do Departamento de Solos, Universidade Federal de Santa Maria, Av. Roraima, 1000, CEP 97105-900, Santa Maria (RS). Bolsista CNPq. rodrigo@ufsm.br

5. Acadêmico do curso de Agronomia, Universidade Federal de Santa Maria, Av. Roraima, 1000, CEP 97105-900, Santa Maria (RS). marcosleandrors@hotmail.com

6. Farmacêutica, Dr ${ }^{\mathrm{a}}$., Professora da Universidade Estadual de Campinas, Av. Anchieta, 200, CEP 13015-904, Campinas (SP). helena@fea.unicamp.br

7. Farmacêutico, Dr., Professor do Instituto de Ciência e Tecnologia (ICT), Universidade Federal dos Vales do Jequitinhonha e Mucuri (UFVJM), Rodovia MGT 367, Km 583, no 5000, CEP 39100-000, Diamantina (MG). stanislau@ict.ufvjm.edu.br

Recebido para publicação em 14/04/2011 e aceito em 21/09/2011 
ectomycorrhizal isolates has shown to be efficient and to increase the mycelial mass of the fungus.

Keywords: mycelium growth; secondary metabolites, production of inoculum.

\section{INTRODUÇÃO}

Nas últimas décadas, o interesse pela utilização dos fungos ectomicorrízicos inoculados a espécies florestais se intensificou devido aos benefícios que estes proporcionam às plantas (SMITH e READ, 2008). A inoculação ectomicorrízica torna possível o estabelecimento de espécies florestais em solos que apresentam condições subadequadas de disponibilidade de nutrientes, ou mesmo com presença de poluentes (BRUNNER, 2001; ROSSI et al., 2002; SOUZA et al., 2006). No entanto, a micorrização controlada de essências florestais exige não somente a seleção de espécies fúngicas eficientes em formar simbiose com a planta (OLIVEIRA e GIACHINI, 1999; ROSSI et al., 2002), mas a multiplicação em larga escala destes isolados fúngicos, possibilitando a inoculação adequada das mudas florestais.

Segundo Pera e Parladé (2005), as micorrizas são consideradas a simbiose de maior expressão ecológica e econômica entre fungos do solo e raízes de plantas superiores. Os fungos ectomicorrízicos, além de estarem envolvidos na ciclagem de nutrientes em ecossistemas arbóreos (HÖGBERG e HÖGBERG, 2002; HOBBIE, 2006; COURTY et al., 2010), desempenham funções fundamentais no estabelecimento e na manutenção de comunidades florestais (SMITH e READ, 2008).

$\mathrm{Na}$ simbiose mutualística ocorre uma micotrofia, onde os fungos, além de proporcionarem ao hospedeiro maior absorção de água e nutrientes minerais essenciais ao seu desenvolvimento, conferem às raízes maior tolerância a estresses bióticos e abióticos (ZEPPA et al., 2005; SMITH e READ, 2008). Em contrapartida, a planta libera na forma de exudatos radiculares, alguns fotossintatos, compostos orgânicos e aminoácidos, beneficiando o desenvolvimento miceliano e a manutenção da simbiose (ZEPPA et al., 2005; SOUZA et al., 2006; SMITH e READ, 2008; NEHLS et al., 2010).

Durante a formação da simbiose ectomicorrízica, ocorrem algumas alterações fisiológicas na planta hospedeira que irão determinar a compatibilidade ou não com o fungo. Estas alterações compreendem desde modificações morfológicas nas raízes até a formação e deposição de exudatos radiculares e compostos fenólicos, dependendo do isolado ectomicorrízico utilizado (BAPTISTA et al., 1999; SMITH e READ, 2008).

Os compostos fenólicos ou essências vegetais são compostos de origem natural, que podem ser obtidos pela hidrodestilação de tecidos vegetais, recebendo a denominação de óleos essenciais (SALGADO e CAMPOS, 2003), os quais estão envolvidos nas interações entre plantas e microrganismos (SIMIONATTO, 2004), atuando na adaptabilidade da planta ao ambiente em que se encontram (MATOS, 2004). Atualmente, a utilização de metabólitos secundários, devido às propriedades encontradas nos terpenos, monoterpenos e sesquiterpenos presentes nestes compostos, representa uma alternativa biotecnológica no manejo de microrganismos patogênicos ou simbiontes do solo (LUDLEY et al., 2009; BÂ et al., 2010).

Embora os metabólitos secundários ou óleos essenciais estejam relacionados com diversas funções necessárias à sobrevivência da planta, exercendo papel fundamental na defesa do vegetal contra a ação de microrganismos (OLUMA e GARBA, 2004; DEL GIUDICE et al., 2008; MAFFEI et al., 2010; SHRIVASTAVA et al., 2010), alguns trabalhos descrevem que os efeitos aleloquímicos dos compostos fenólicos podem assumir diferentes formas de ação sobre o desenvolvimento de organismos (BRIMECOMBE et al., 2001), inibindo determinado organismo (SCHAWN-ESTRADA et al., 2003; MEDICE et al., 2007) ou estimulando seu desenvolvimento, dependendo da concentração de uso e da interação entre os compostos (MARTINS et al., 2000; STEFFEN et al., 2010).

No caso da associação ectomicorrízica, a formação da simbiose fungo-planta depende, de forma direta, das condições biológicas dos exudatos radiculares e das condições físico-químicas da rizosfera (SOUZA et al., 2006). Segundo Baptista et al. (1999), Menotta et al. (2004), Martin et al. (2008) e Smith e Read (2008), o quimiotropismo é estabelecido pela exudação de compostos fenólicos pelas raízes da planta hospedeira, os quais atuam como sinalizadores bioquímicos e estabilizadores da simbiose ectomicorrízica.

Em florestas de coníferas, Koide et al. (1998) observaram que a decomposição dos resíduos vegetais sobre o solo resulta em acúmulo de metabólitos secundários, os quais influenciam no 
crescimento de fungos ectomicorrízicos, limitando sua associação com as raízes das plantas. Com base nestes dados, Kainulainen et al. (2003) verificaram que em comunidades florestais, a liteira em decomposição é responsável pela liberação de metabólitos secundários, que estabelecem, dependendo da concentração, a relação de espécies de fungos capazes de tolerar estes compostos e formar simbiose com a planta.

Esforços estão sendo concentrados não somente no aprimoramento de metodologias para fabricação de inoculantes micorrízicos, mas também na otimização do desenvolvimento micelial, buscando-se compostos orgânicos com capacidade de bioestimulação do crescimento fúngico, visando à maior produção de material para ser utilizado nos programas de micorrização. Partindo-se do conhecimento sobre as interações estabelecidas na simbiose entre os fungos ectomicorrízicos e o sistema radicular de plantas e do conceito sobre a síntese e constituição dos óleos essenciais, o objetivo nesse trabalho foi determinar a ação bioestimuladora do óleo essencial de Eucalyptus grandis no crescimento de isolados ectomicorrízicos in vitro.

\section{MATERIAL E MÉTODOS}

O experimento foi constituído pela utilização do óleo essencial de Eucalyptus grandis em diferentes concentrações, visando determinar a concentração na qual ocorreria máxima estimulação do micélio fúngico. $\mathrm{O}$ trabalho foi realizado em três etapas: (1) extração do óleo essencial de Eucalyptus grandis por hidrodestilação (SERAFINI e CASSEL, 2001) e caracterização dos compostos obtidos; (2) avaliação do efeito do óleo essencial de Eucalyptus grandis como bioestimulador do desenvolvimento in vitro de sete isolados de fungos ectomicorrízicos e (3) caracterização morfométrica dos isolados de fungos ectomicorrízicos inoculados em meio de cultura líquido contendo óleo essencial de eucalipto.

\section{Obtenção do óleo essencial de Eucalyptus grandis}

A extração do óleo essencial foi realizada através da técnica de hidrodestilação das folhas frescas de eucalipto (VITTI e BRITO, 2003). As folhas coletadas foram cortadas em pedaços de $2 \mathrm{~cm}$, pesadas e separadas em lotes individuais de $100 \mathrm{~g}$. Posteriormente, as folhas foram colocadas em balão de fundo redondo no aparelho de Clevenger modificado (SERAFINI e CASSEL, 2001), mantendo- -se água destilada em ebulição dentro do balão, por meio de aquecedor externo. Os componentes vegetais extraídos, após a passagem do destilado por um condensador tipo Liebig, foram coletados e mantidos sob refrigeração a $4{ }^{\circ} \mathrm{C}$, até sua utilização.

\section{Isolados de fungos ectomicorrízicos}

Utilizaram-se os fungos ectomicorrízicos das espécies Pisolithus sp. (isolados UFSC Pt 24 e UFSC Pt 188), Pisolithus microcarpus (isolado UFSC Pt 116), Chondrogaster angustiporus (isolado UFSC Ch 163), Scleroderma citrinum (isolado UFSC Sc 124) e Suillus sp. (isolados UFSM RA 2.2 e UFSM RA 2.8) coletados em plantações de eucalipto. Os isolados foram mantidos em meio de cultura sólido Melin-Norkrans modificado MNM (MARX, 1969) em pH 5,8, em placas de Petri de $90 \mathrm{~mm}$ de diâmetro. O material foi mantido em estufa a $26^{\circ} \mathrm{C}$ e multiplicado a partir de culturas da coleção, através de repicagens para o meio da mesma composição, sob condições assépticas.

\section{Determinação dos compostos presentes no óleo essencial}

Para a caracterização dos compostos, o óleo essencial foi seco sob sulfato de sódio anidro e recolhido em recipiente para fins de quantificação do rendimento do óleo.

Para as análises cromatográficas foram utilizados: cromatógrafo marca Varian ${ }^{\circledR} 3800$ dotado de detector de ionização de chama FID e equipado com o programa Star Chromatography Workstation (versão 4.5); e cromatógrafo marca Shimadzu GC17A dotado de espectrômetro de massas Shimadzu ${ }^{\circledR}$ modelo QP5000. Em ambos os equipamentos, empregou-se coluna capilar $\mathrm{SPB}^{\mathrm{TM}}-5(30 \mathrm{~m} \times 0.25 \mathrm{~mm}$ i.d. x $0.25 \mu \mathrm{m}$ de fase estacionária) da Supelco (BELLEFONTE, PA, USA). Os espectros de massa obtidos foram comparados com os espectros do site da NIST (http://webbook.nist.gov/chemistry/) na internet.

\section{Avaliação do óleo essencial de Eucalyptus grandis sobre o desenvolvimento de isolados de fungos ectomicorrízicos in vitro}

Para a avaliação do efeito das diferentes concentrações do óleo essencial de Eucalyptus grandis sobre o desenvolvimento dos isolados ectomicorrízicos, foram utilizados Erlenmeyers de $125 \mathrm{~mL}$, contendo $25 \mathrm{~mL}$ de meio de cultura Melin-Norkrans modificado MNM (MARX, 1969) líquido com pH 5,8. Após a esterilização e o res- 
friamento dos Erlenmeyers a temperatura ambiente, adicionou-se as concentrações de $0,10,20,30$, $40,50,60,70,80,90$ e $100 \mu \mathrm{L} \mathrm{L}^{-1}$ do óleo essencial, previamente solubilizado em etanol 96,5\% na proporção de $1: 1(\mathrm{v} / \mathrm{v})$, conforme metodologia proposta por Fabrowski et al. (2003). Após a adição do óleo essencial ao meio de cultura, foram inoculados dois discos de $10 \mathrm{~mm}$ de diâmetro do micélio fúngico retirado das bordas de crescimento em meio de cultura sólido. O material foi mantido em incubadora a $26{ }^{\circ} \mathrm{C}$ por 25 dias no escuro.

A fim de se conhecer a interferência do etanol no crescimento fúngico, acrescentou-se um tratamento controle contendo apenas meio de cultura Melin-Norkrans modificado MNM (MARX, 1969) líquido e etanol na concentração utilizada para solubilizar a concentração mais elevada de óleo essencial.

Após a montagem das unidades experimentais, as mesmas foram incubadas por 25 dias, a $26{ }^{\circ} \mathrm{C} \pm 0,2$ no escuro. Terminado o período de incubação, os micélios foram retirados dos Erlenmeyers sob filtração em papel Watman $n^{\circ}$ 3 e lavados em água destilada sobre peneira de $0,037 \mathrm{~mm}$. Em seguida, foram secos em estufa a $65^{\circ} \mathrm{C}$ sob ventilação forçada durante 72 horas, a fim de determinar a massa seca dos micélios fúngicos.

As regressões foram obtidas pelo software Table Curve (JANDEL SCIENTIFIC, 1991). Para a determinação dos tratamentos mais eficientes quanto ao bioestímulo do desenvolvimento miceliano, os dados obtidos nos tratamentos foram transformados para raiz quadrada de $\mathrm{x}+0,1$ e submetidos à análise de variância e ao teste de médias pelo teste de Tukey a $5 \%$ de probabilidade de erro pelo software SISVAR (FERREIRA, 2000).

\section{Características morfológicas das hifas}

Após a determinação dos isolados fúngicos que melhor responderam à adição de óleo essencial ao meio de cultura e da concentração ideal do óleo essencial, estes isolados foram avaliados quanto (1) à evolução do crescimento in vitro dos isolados ectomicorrízicos expostos ao óleo essencial em relação ao tratamento controle e (2) às características morfológicas das hifas fúngicas crescidas em meio de cultura líquido contendo o óleo essencial.

Para a avaliação da evolução do crescimento miceliano, os isolados ectomicorrízicos foram inoculados em $25 \mathrm{~mL}$ de meio de cultura Melin-Norkrans modificado MNM líquido a $\mathrm{pH}$
5,8 (MARX, 1969), em Erlenmeyers de $125 \mathrm{~mL}$. Após a adição do óleo essencial ao meio de cultura, inocularam-se 2 discos de $10 \mathrm{~mm}$ de diâmetro do micélio fúngico em cada Erlenmeyer. $\mathrm{O}$ material foi mantido em incubadora por 25 dias, a $26^{\circ} \mathrm{C}$ $\pm 0,2$ no escuro, com seis repetições. As avaliações foram realizadas a cada cinco dias.

Para a avaliação das características morfométricas dos isolados ectomicorrízicos, utilizaram-se lâminas de microscopia, sobre as quais foram acoplados cânulos de vidro de $1,5 \mathrm{~mm}$ de diâmetro. Sobre esta estrutura, colocou-se uma lamínula de microscopia de forma que houvesse espaço entre a lâmina e a lamínula, formando a unidade experimental. No espaço entre as lâminas, adicionou-se $500 \mu \mathrm{L}$ de meio de cultura Melin-Norkrans modificado MNM líquido a pH 5,8 (MARX, 1969). Foram utilizadas três concentrações de óleo essencial de eucalipto: (1) tratamento controle (sem a adição do óleo essencial), (2) concentração do óleo essencial que proporcionou melhor resposta ao estímulo do crescimento miceliano $\left(20 \mu \mathrm{L} \mathrm{L}^{-1}\right.$ para os isolados UFSC Pt 116 e UFSC Pt 24) e (3) concentração do óleo essencial que resultou em menor crescimento miceliano $\left(40 \mu \mathrm{L} \mathrm{L}^{-1}\right.$ para os isolados UFSC Pt 116 e $50 \mu \mathrm{L} \mathrm{L}^{-1}$ para o isolado UFSC Pt 24).

Cada unidade experimental foi acomodada sobre suporte de $5 \mathrm{~mm}$ de altura dentro de uma placa de Petri, com diâmetro de $90 \mathrm{~mm}$, contendo água destilada estéril, a fim de proporcionar um ambiente úmido evitando a desidratação do meio de cultura.

As unidades experimentais permaneceram em incubadora a $26^{\circ} \mathrm{C} \pm 0,2$ no escuro por um período de cinco dias. Decorrido este período, retirou-se os cânulos de vidro, forçando o contato entre a lâmina e a lamínula de vidro para visualização do crescimento das hifas em microscópio.

Cada conjunto (lâmina + lamínula) foi avaliado e fotografado em máquina fotográfica digital marca Sony, acoplada ao microscópio óptico com aumento de 300 vezes. As imagens obtidas foram ampliadas no software GIMP 2.4.5 (GNU Image Manipulation Program), onde se avaliou o diâmetro médio das hifas. Os dados obtidos nas imagens foram transformados para raiz quadrada de $\mathrm{x}+$ 0,1 e submetidos à análise de variância e ao teste de médias pelo teste de Tukey a $5 \%$ de probabilidade de erro pelo software SISVAR (FERREIRA, 2000), tomando-se como base os níveis de significância maiores que $95 \%(\mathrm{p} \leq 0,05)$. 


\section{RESULTADOS E DISCUSSÃO}

No óleo essencial de Eucalyptus grandis foram identificados 40 compostos (Tabela 1), Estes compostos corroboram com os descritos na literatura referente à composição de óleos essenciais extraídos de plantas do gênero Eucalyptus (BARANSKA et al., 2005).

Dentre estes componentes, o monoterpeno 1,3,3-trimetil-2-oxabiciclo[2.2.2]-octano, conhecido como eucaliptol (1,8-Cineol) destacou-se em proporção em relação aos demais. García et al. (2009) atribuem os efeitos de inibição ou bioestímulo do crescimento vegetal e microbiano principalmente ao eucaliptol, seguido pelo citral, timol, $\alpha$ e $\beta$-pineno, cetonas e compostos flavônicos. Estes compostos, dependendo da concentração, podem proporcionar relações de sinergismo, resultando na indução do crescimento de microrganismos ou plantas (LAGRANGE et al., 2001; LUDLEY et al., 2009). Segundo Estanislau et al. (2001), provavelmente este efeito esteja relacionado ao fato do eucaliptol interagir com radicais livres contendo radical hidroxila, inibindo a produção de substâncias oxigenadas reativas.

Alguns compostos vegetais, quando utili- zados em concentrações extremamente reduzidas, podem proporcionar efeito Hormese no crescimento microbiano. Segundo Forbes (2000), este efeito se caracteriza pela indução de determinadas características provocadas pela utilização de baixas concentrações de compostos considerados tóxicos. Baseados nesta característica, alguns trabalhos demonstram atividade de óleos essenciais na bioestimulação do desenvolvimento microbiano (MARTINS et al., 2000; LUDLEY et al., 2009).

As concentrações de óleo essencial que proporcionaram incrementos no crescimento miceliano fúngico encontram-se entre 10 e $30 \mu \mathrm{L} \mathrm{L}^{-1}$, dependendo do isolado ectomicorrízico utilizado (Figura 1).

No entanto, o isolado UFSC Pt 188 (Pisolithus microcarpus) apresentou maior crescimento no meio de cultura sem a adição do óleo essencial, uma vez que o óleo, mesmo na concentração de $10 \mu \mathrm{L} \mathrm{L}^{-1}$, apresentou efeito negativo sobre $\mathrm{o}$ isolado.

Os isolados UFSC Sc 124 (Scleroderma citrinum), UFSC Ch 163 (Chondrogaster angustiporus) e UFSM RA 2.8 (Suillus sp.) apresentaram maior crescimento quando da adição de $10 \mu \mathrm{L} \mathrm{L}^{-1}$ de óleo essencial de eucalipto ao meio

TABELA 1: Componentes do óleo essencial extraído de folhas frescas de Eucalyptus grandis.

TABLE 1: Components of the Eucalyptus grandis essential oil extracted from fresh leaves.

\begin{tabular}{lcclcc}
\hline \multicolumn{1}{c}{ Composto } & PR $(\%)^{1}$ & & \multicolumn{2}{c}{ Composto } & PR $(\%)^{1}$ \\
\cline { 1 - 2 } Eucalyptol (1,8-cineol) & 9,87 & & Tenuifoleno & 0,62 \\
p-Cymeno & 7,87 & & Terpinen-4-ol & 0,57 \\
Spathulenol & 6,58 & & Camphene & 0,55 \\
Lepidozenal & 4,89 & & Bergamotol & 0,41 \\
Cubeb-11-ene & 3,89 & & 8,9 -Epoxyselina-4,11-diene & 0,39 \\
Junenol & 3,48 & & Eudesma-1,4(15),11-triene & 0,38 \\
4(15)-Dehydroglobulol & 3,20 & & (E)-Caryophyllene & 0,36 \\
Deca-4,8-dienol, 1-ethynyl-1,5,9-trimethyl- & 2,42 & & Neryl acetate & 0,28 \\
$\alpha$-Phellandrene & 2,26 & & $\gamma$-Terpineno & 0,28 \\
allo-Aromadendra-4(15),10(14)-diene & 2,00 & & Longipinene epoxide & 0,27 \\
(E)-Nerolidol & 1,95 & & $\beta$-Myrcene & 0,25 \\
$\alpha$-Humulene & 1,87 & & $\alpha$-Muurolene & 0,23 \\
$\alpha$-Guaiol & 1,70 & & Elemene & 0,19 \\
T-Cadinol & 1,28 & & Bisabolene & 0,14 \\
Germacrene $B$ & 0,95 & & $\alpha$-Farnesene & 0,12 \\
$\gamma$-Himalacheno & 0,84 & & (E)-3(10)-caren-4-ol & 0,11 \\
Guaia-6,10(14)-diene $4 \beta$--ol & 0,84 & & Terpinoleno & 0,10 \\
$\alpha$-Terpineol & 0,76 & & Epiglobulol & 0,09 \\
Eremoligenol & 0,74 & & $\beta$-Pineno & 0,08 \\
Eudesm-11-en-4alfa-ol & 0,73 & & Hinesol & 0,08 \\
\hline
\end{tabular}

Em que: ${ }^{1} \mathrm{PR}=$ Porcentagem Relativa em relação ao total extraído. 


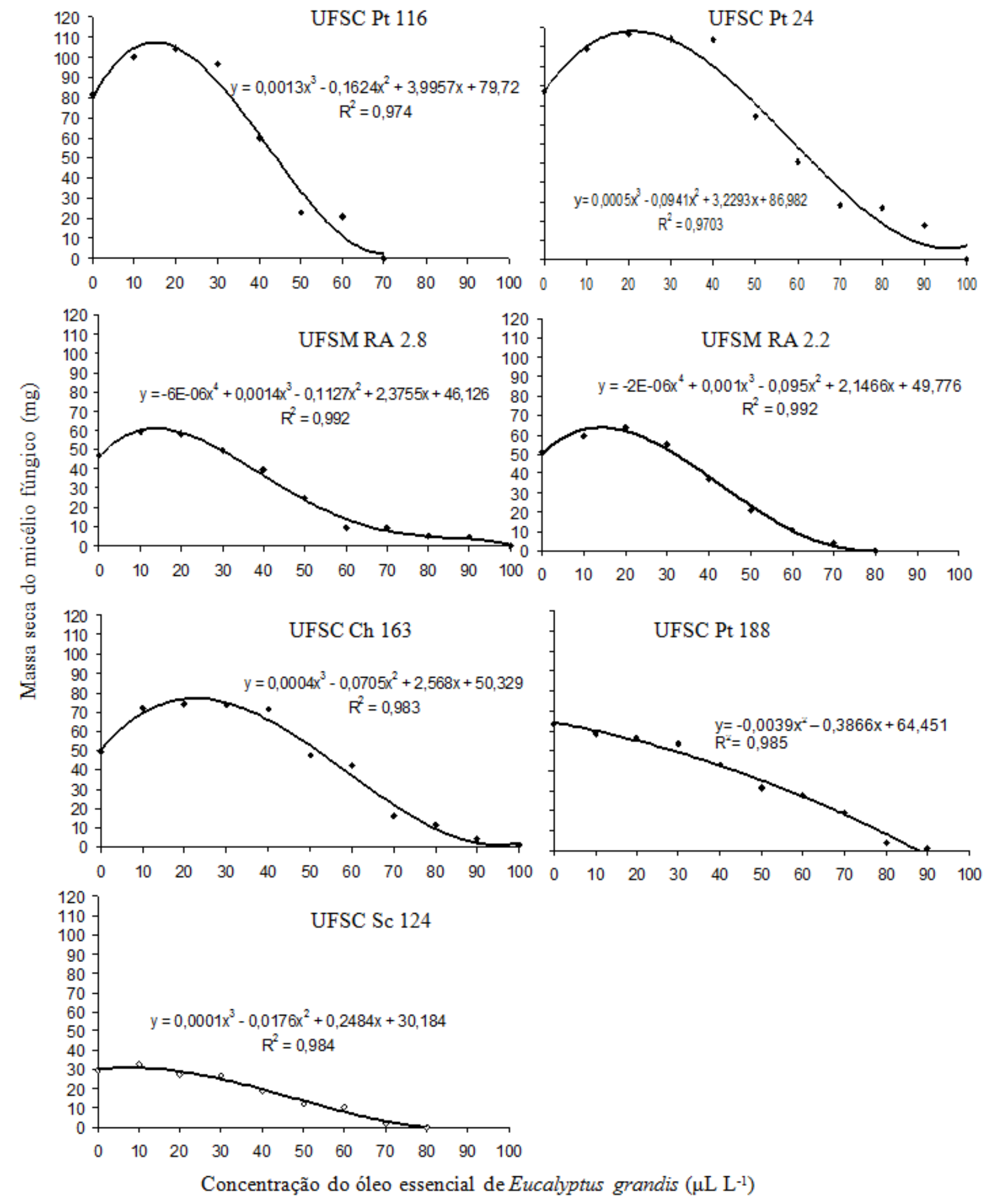

FIGURA 1: Crescimento miceliano in vitro de isolados ectomicorrízicos (UFSC Pt 116, UFSC Pt 24, UFSM RA 2.8, UFSM RA 2.2, UFSC Ch 163, UFSC Pt 188 e UFSC SC 124) em meio de cultura líquido contendo concentrações crescentes de óleo essencial de Eucalyptus grandis.

FIGURE 1: Growth in vitro mycelium of ectomycorrhizal isolates (UFSC Pt 116, Pt 24 UFSC, UFSM RA 2.8, UFSM RA 2.2, UFSC Ch 163, UFSC Pt 188 and UFSC SC 124) in liquid culture medium containing increasing concentrations of Eucalyptus grandis essential oil. 
de cultura. Já, os isolados UFSC Pt 116 (Pisolithus microcarpus), UFSC Pt 24 (Pisolithus sp.) e UFSM RA 2.2 (Suillus sp.) apresentaram maior crescimento com a adição de $20 \mu \mathrm{L} \mathrm{L}^{-1}$ de óleo essencial.

De forma geral, os efeitos da utilização dos óleos essenciais, tanto no controle de microrganismos como no bioestímulo do crescimento destes, podem ser atribuídos aos compostos fenólicos e terpenos, com ênfase aos monoterpenos e sesquiterpenos presentes na composição dos metabólitos secundários de plantas bioativas (TAIZ e ZEIGER, 2004).

Avaliando o crescimento de isolados de fungos ectomicorrízicos em substratos contendo diferentes concentrações de metabólitos secundários, Ludley et al. $(2008,2009)$ observaram variação significativa, tanto de inibição como de estímulo dos isolados, dependendo da espécie ectomicorrízica e da concentração dos metabólitos. Segundo os autores, o comportamento das espécies ectomicorrízicas frente à presença de metabólitos secundários é fundamental para a seleção de isolados capazes de formar simbiose com determinada comunidade de plantas.

De acordo com Taiz e Zeiger (2004), os compostos fenólicos, compostos contendo grupos fenóis, um grupo hidroxila e um anel aromático, apresentam grande variedade de funções nas espécies vegetais, atuando como sinal bioquímico na simbiose de plantas e microrganismos mutualistas.

Segundo Ludley et al. (2009), os resultados referentes à ação de óleos essenciais no estímulo ou na inibição do crescimento de microrganismos não estão somente relacionados ao tipo de compostos presentes nos óleos, mas sim no comportamento dose-efeito. Segundo os autores, embora alguns metabólitos secundários sejam essenciais para o desenvolvimento e crescimento miceliano, determinados compostos, quando em concentrações elevadas, causam retardo ou até mesmo limitam a expansão das hifas de isolados ectomicorrízicos. De acordo com Atanda et al. (2007), os óleos essenciais de Cinnamomun cassia Blume e Laurus nobilis L. estimularam o crescimento micelial in vitro de Aspergillus parasiticus.

Em concentrações de óleo essencial acima de $30 \mu \mathrm{L} \mathrm{L}^{-1}$, observa-se diminuição do crescimento fúngico, evidenciado pela menor massa seca do micélio (Tabela 2). Soliman e Badeaa (2002) em estudos quanto ao efeito de óleos essenciais de plantas bioativas sobre micotoxinas e fungos patogênicos, observaram que a inibição do crescimento fúngico está diretamente relacionada à concentração dos compostos presentes nos óleos. Singh et al. (2003) observaram efeito inibitório sobre o crescimento fúngico, utilizando óleos essenciais de plantas bioativas em concentrações superiores a $1000 \mu \mathrm{L} \mathrm{L}^{-1}$.

Em comparação à massa seca do micélio no tratamento controle, o fungo ectomicorrízico Chondrogaster angustiporus (isolado UFSC $\mathrm{Ch}$ 163) foi o que apresentou melhor resposta à adição do óleo essencial no meio de cultura líquido (incremento de $49,13 \%$ ). No entanto, este isolado apresenta crescimento lento em meio de cultura, sendo sua massa micelial significativamente inferior aos iso-

TABELA 2: Massa seca do micélio fúngico $(\mathrm{mg})$ dos isolados ectomicorrízicos incubados na presença do óleo essencial de Eucalyptus grandis. Média de seis repetições (n=6).

TABLE 2: Dry mass of mycelium $(\mathrm{mg})$ of ectomycorrhizal isolates incubated in the presence of Eucalyptus grandis essential oil. Average of six replicates $(\mathrm{n}=6)$.

\begin{tabular}{lllc}
\hline \multicolumn{1}{c}{ Fungo ectomicorrízico } & \multicolumn{1}{c}{$\mathrm{MSC}^{1}$} & $\mathrm{MSCAL}^{2}$ & $\mathrm{MSOE}^{3}$ \\
\hline Pisolithus sp. (UFSC Pt 24) & $87,24 \mathrm{a} \mathrm{B}^{*}$ & $91,32 \mathrm{a} \mathrm{B}$ & $116,65 \mathrm{a} \mathrm{A}$ \\
Pisolithus microcarpus (UFSC Pt 116) & $81,45 \mathrm{a} \mathrm{B}$ & $81,69 \mathrm{ab} \mathrm{B}$ & $106,57 \mathrm{a} \mathrm{A}$ \\
Pisolithus microcarpus (UFSC Pt 188) & $63,47 \mathrm{~b} \mathrm{~A}$ & $66,07 \mathrm{bc} \mathrm{A}$ & $63,47 \mathrm{bc} \mathrm{A}$ \\
Chondrogaster angustiporus (UFSC Ch 163) & $49,52 \mathrm{bc} \mathrm{B}$ & $55,00 \mathrm{c} \mathrm{B}$ & $73,85 \mathrm{~b} \mathrm{~A}$ \\
Suillus sp. (UFSM RA 2.2) & $49,15 \mathrm{bc} \mathrm{B}$ & $53,47 \mathrm{c} \mathrm{AB}$ & $60,05 \mathrm{c} \mathrm{A}$ \\
Suillus sp. (UFSM RA 2.8) & $46,80 \mathrm{bc} \mathrm{B}$ & $48,85 \mathrm{~cd} \mathrm{~B}$ & $59,10 \mathrm{c} \mathrm{A}$ \\
Scleroderma citrinum (UFSC Sc 124) & $30,07 \mathrm{c} \mathrm{A}$ & $31,40 \mathrm{~d} \mathrm{~A}$ & $32,37 \mathrm{~d} \mathrm{~A}$ \\
\hline CV (\%) & 8,95 & 7,60 & 6,96 \\
\hline
\end{tabular}

Em que: ${ }^{1}$ Massa seca do micélio no tratamento controle. ${ }^{2}$ Massa seca do micélio no tratamento controle álcool. ${ }^{3}$ Massa seca do micélio no tratamento com a concentração de óleo essencial de maior eficiência. UFSC Pt 24 (20 $\mu \mathrm{L}$ $\left.\mathrm{L}^{-1}\right)$, UFSC Pt $116\left(20 \mu \mathrm{L} \mathrm{L}^{-1}\right)$, UFSC Pt $188\left(0 \mu \mathrm{L} \mathrm{L}^{-1}\right)$, UFSC Ch $163\left(10 \mu \mathrm{L} \mathrm{L}^{-1}\right)$, UFSM RA $2.2\left(20 \mu \mathrm{L} \mathrm{L}^{-1}\right)$, UFSM RA $2.8\left(10 \mu \mathrm{L} \mathrm{L}^{-1}\right)$ e UFSC Sc $124\left(10 \mu \mathrm{L} \mathrm{L}^{-1}\right)$. Médias seguidas da mesma letra minúscula nas colunas e maiúscula nas linhas não diferem entre si pelo teste de Tukey a $5 \%$ de probabilidade. ** Coeficiente de variação. 
lados pertencentes ao gênero Pisolithus (Tabela 2). Desta forma, o fECM Chondrogaster angustiporus não apresenta características ideais para ser utilizado em programas de produção de inóculo em larga escala.

A utilização do álcool como solubilizante do óleo essencial, demonstrado pela massa seca do micélio no tratamento álcool (MSCAL), não afetou o crescimento miceliano. Apenas para o fungo ectomicorrízico Suillus sp. (isolado UFSM RA 2.2), a presença do álcool no meio de cultura resultou em aumento no crescimento miceliano (Tabela 2).

Estudando o efeito da utilização do óleo essencial de Eucalyptus spp. no controle de fungos do gênero Aspergillus, García et al. (2009) observaram que a oxidação provocada pelo composto eucaliptol (1,8-cineol) provocou a formação dos compostos 2-exo-hydroxi-1,8-cineol, 2-endo-hydroxi-1,8 cineol, 3-exo-hydroxi-1,8-cineol e 3-endo-hydroxi-1,8-cineol, os quais resultaram na inativação do patógeno. Já Bakkali et al. (2008) observaram que os componentes aromáticos e alifáticos presentes nos metabólitos secundários dos vegetais podem atuar como pró-oxidantes danosos, afetando as membranas celulares dos organismos, ou como antioxidantes benéficos, beneficiando a manutenção e o desenvolvimento celular, dependendo da concentração e natureza.
Analisando-se o crescimento miceliano dos isolados UFSC Pt 116 e UFSC Pt 24 durante o período de incubação, verifica-se que ao final de 25 dias, estes apresentaram crescimento significativamente superior quando inoculados em meios de cultura com a adição de $20 \mu \mathrm{L} \mathrm{L}^{-1}$ de óleo essencial. No entanto, este maior crescimento começa a ser evidente apenas entre $o 10^{\circ}$ e $15^{\circ}$ dias de incubação para ambos isolados (Figura 2).

Desde a repicagem do material (tempo zero) até o $5^{\circ}$ dia de incubação, a adição ou não do óleo essencial não alterou o crescimento miceliano de ambos os isolados. A partir do $5^{\circ}$ dia de incubação, no tratamento controle, no qual não se adicionou o óleo essencial, os isolados apresentaram crescimento acelerado, sendo este evidenciado até o $10^{\circ}$ dia de incubação (Figura 2). A partir do $10^{\circ}$ dia, ambos os isolados (UFSC Pt 116 e UFSC Pt 24) apresentaram diminuição na taxa de crescimento, permanecendo até o $15^{\circ}$. Durante este período, os tratamentos onde foi utilizado o óleo essencial na concentração de $20 \mu \mathrm{L} \mathrm{L}^{-1}$ de meio de cultura apresentaram crescimento contínuo e linear até o término do período de incubação.

A partir do $15^{\circ}$ dia, os isolados incubados no tratamento controle apresentam crescimento mais acelerado, não sendo observada diminuição no crescimento até o término do período de incubação.

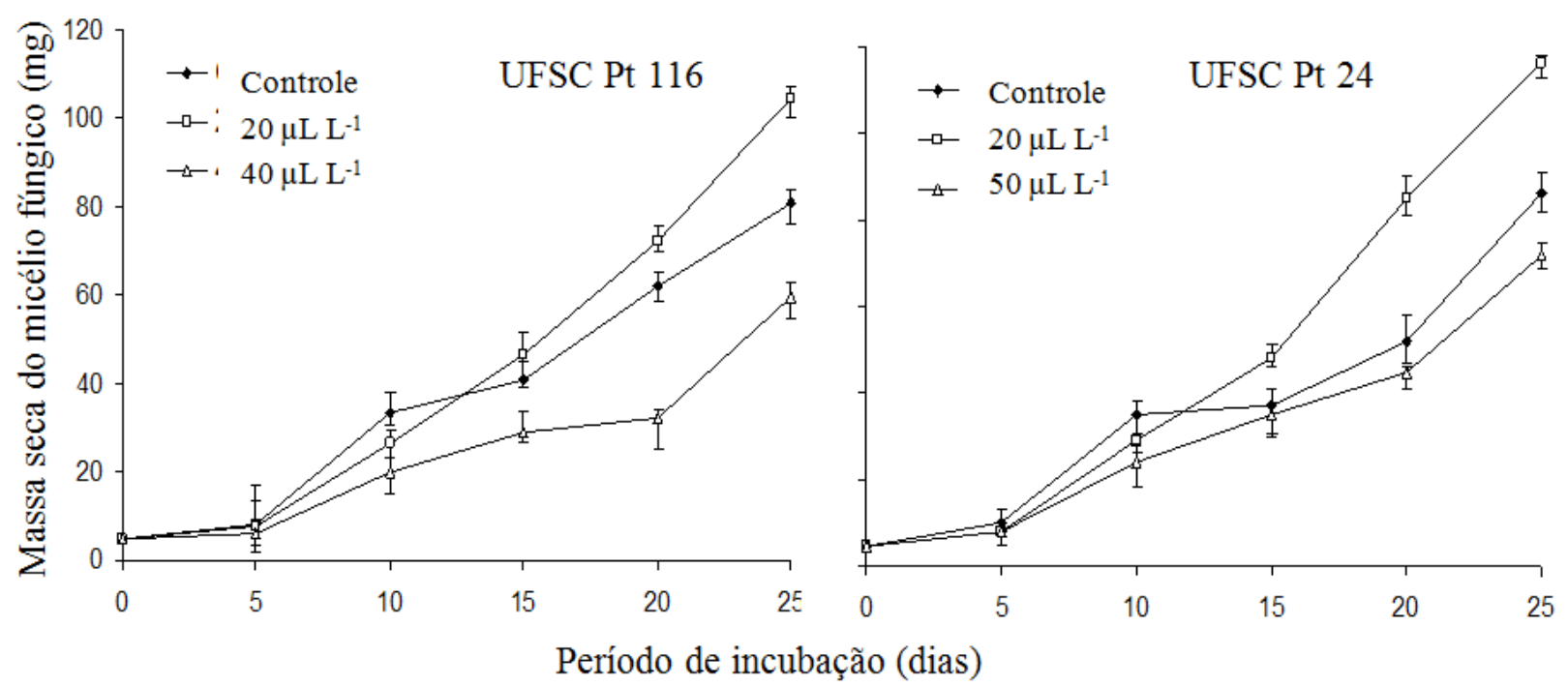

FIGURA 2: Curva de crescimento do micélio dos fungos ectomicorrízicos Pisolithus microcarpus (UFSC Pt 116) e Pisolithus sp. (UFSC Pt 24) em meio líquido contendo diferentes concentrações do óleo essencial de eucalipto.

FIGURE 2: Curve of growth of mycelium of the ectomycorrhizal Pisolithus microcarpus (UFSC Pt 116) and Pisolithus sp. (UFSC Pt 24) in liquid medium containing different concentrations of eucalyptus essential oil. 
Os isolados UFSC Pt 116 e UFSC Pt 24, nos tratamentos onde se aplicaram as concentrações de óleo essencial que limitaram o crescimento fúngico, igualando-se ao tratamento controle (Figura 1), apresentaram crescimento miceliano inferior aos demais tratamentos a partir do $5^{\circ}$ dia de incubação. No entanto, este tratamento não limitou o crescimento miceliano no período do $10^{\circ}$ ao $15^{\circ}$ dia, observado no tratamento controle.

Verificou-se que a adição de $20 \mu \mathrm{L} \mathrm{L}^{-1}$ do óleo essencial de eucalipto no meio de cultura líquido resultou em maior densidade de micélio fúngico, evidenciado pela menor distância entre os pontos de ramificações, pelo maior diâmetro das hifas e maior número de hifas laterais partindo de um mesmo ponto de ramificação (Figuras 3 e 4). Segundo Denny e Wilkins (1987), esta maior densidade de micélio proporciona ao isolado maior grau de sobrevivência no campo e maior eficiência na associação e manutenção da simbiose com plantas simbiontes.
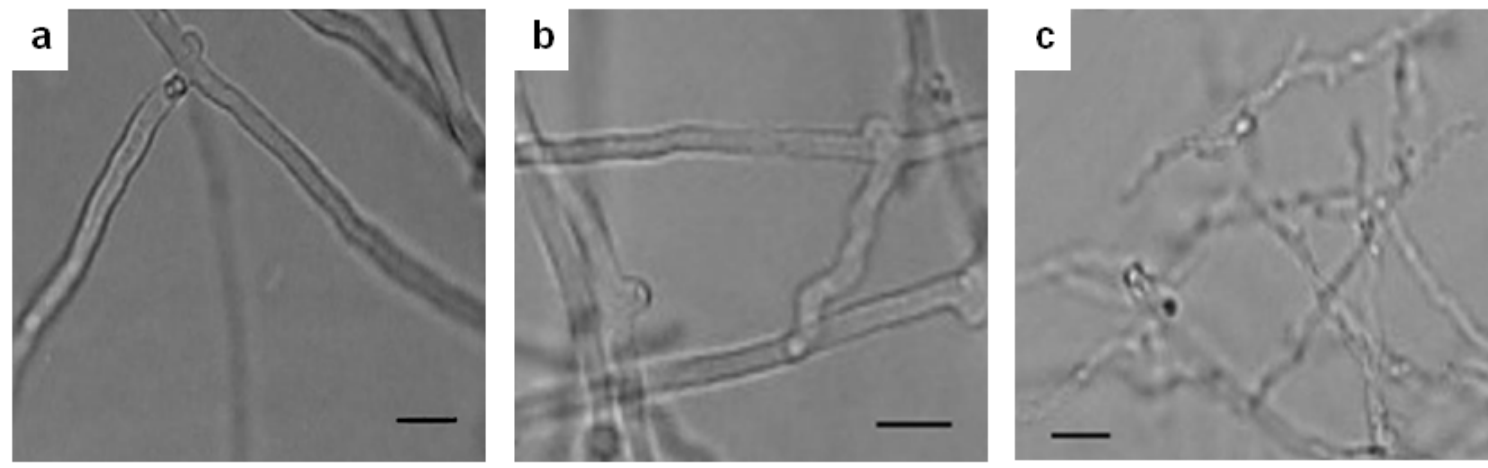

FIGURA 3: Hifas do fungo ectomicorrízico Pisolithus microcarpus (UFSC Pt 116) no tratamento controle (a), tratamento $20 \mu \mathrm{L} \mathrm{L}^{-1}$ do óleo essencial (b) e tratamento $40 \mu \mathrm{L} \mathrm{L}^{-1}$ do óleo essencial (c), cinco dias após a incubação. (barra $=5 \mu \mathrm{m}$ ).

FIGURE 3: Hyphae of the ectomycorrhizal fungus Pisolithus microcarpus (UFSC Pt 116) in control (a) treating $20 \mu \mathrm{L} \mathrm{L}^{-1}$ essential oil (b) treatment and $40 \mu \mathrm{L} \mathrm{L}^{-1}$ essential oil (c) five days after incubation. (bar $=5 \mu \mathrm{m})$.
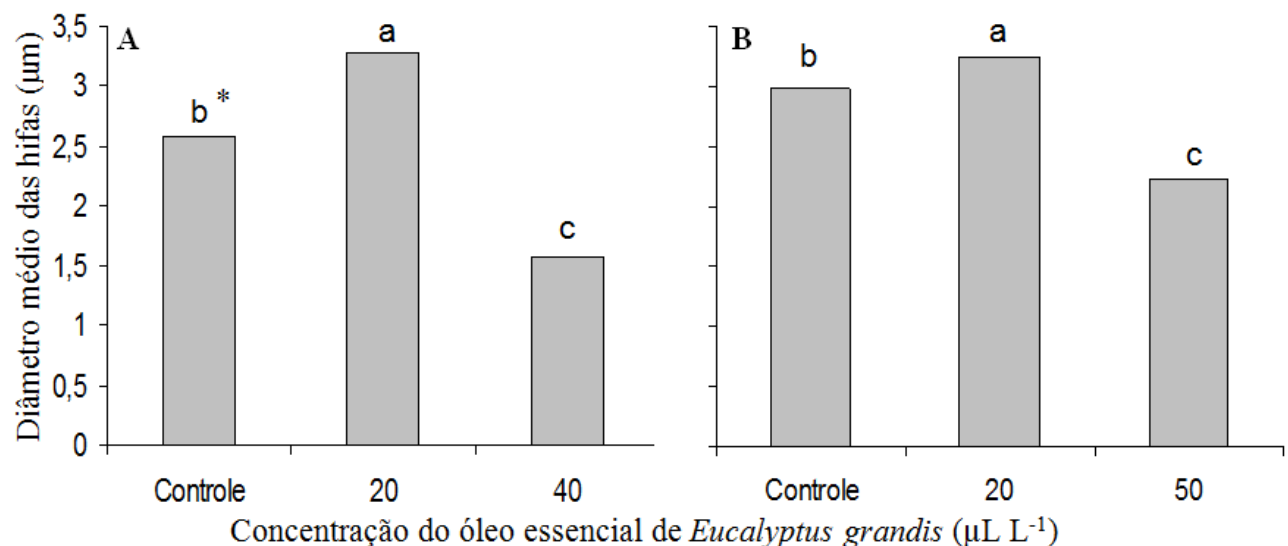

FIGURA 4: Diâmetro médio das hifas dos fungos ectomicorrízicos (A) Pisolithus microcarpus (UFSC Pt 116) nos tratamentos controle, $20 \mu \mathrm{L} \mathrm{L}^{-1}$ e $40 \mu \mathrm{L} \mathrm{L}^{-1}$ e do fungo ectomicorrízico (B) Pisolithus sp. (UFSC Pt 24) nos tratamentos controle, $20 \mu \mathrm{L} \mathrm{L}^{-1}$ e $50 \mu \mathrm{L} \mathrm{L}^{-1}$. Média de seis repetições. * Médias seguidas da mesma letra não diferem entre si pelo teste de Tukey a $5 \%$. UFSC Pt 116 (CV\% 7,15), UFSC Pt 24 (CV\% 8,61).

FIGURE 4: Mean diameter of the hyphae of ectomycorrhizal fungi (A) Pisolithus microcarpus (UFSC Pt 116) the control treatment, $20 \mu \mathrm{L} \mathrm{L}^{-1}$ and $40 \mu \mathrm{L} \mathrm{L}^{-1}$ and the ectomycorrhizal fungus (B) Pisolithus sp. (UFSC Pt 24) the control treatment, $20 \mu \mathrm{L} \mathrm{L}^{-1}$ and $50 \mu \mathrm{L} \mathrm{L}^{-1}$. Average of six replicates. * Means followed by same letter do not differ from Tukey test at $5 \%$. UFSC Pt 116 (CV $7.15 \%$ ), UFSC Pt 24 (CV $8.61 \%$ ). 
O aumento no diâmetro das hifas, devido à adição de $20 \mu \mathrm{L} \mathrm{L}^{-1}$ do óleo essencial de eucalipto ao meio de cultura, resultou em maior massa de micélio fúngico por área. Tendo em vista que, quando da utilização de tubetes, $100 \mathrm{mg}$ de micélio são suficientes para inocular $1 \mathrm{~m}^{2}$ de viveiro, o ganho em massa micelial observado com a adição do óleo essencial possibilita a inoculação de maior número de mudas em relação ao inóculo tradicional (sem a utilização do óleo essencial).

Quando adicionado óleo essencial na concentração de $40 \mu \mathrm{L} \mathrm{L}^{-1}$ e $50 \mu \mathrm{L} \mathrm{L}^{-1}$, houve redução significativa no diâmetro das hifas dos isolados UFSC Pt 116 e UFSC Pt 24, respectivamente. Estas concentrações resultaram em crescimento miceliano abaixo do crescimento observado no tratamento controle (Figura 1).

Além do efeito de estímulo ou limitação do desenvolvimento das hifas fúngicas, evidenciado pelo diâmetro destas, dependendo da concentração do óleo essencial adicionado ao meio de cultura, o óleo proporcionou maior ou menor ramificação das hifas, estabelecendo-se uma relação de dose-efeito. Este padrão de comportamento foi demonstrado por Ludley et al. (2009), em estudos quanto ao desenvolvimento de fungos ectomicorrízicos na presença de determinados compostos presentes no metabolismo secundário de coníferas.

Durante a formação da simbiose micorrízica, observou-se na planta a formação e o acúmulo de polipeptídeos de baixo peso molecular, idênticos aos observados quando da penetração de fungos patogênicos no sistema radicular, evidenciando a reação de mecanismos de defesa (FEUGEY et al., 1999). Observou-se também a indução da quitinase, peroxidase e o estímulo ao metabolismo de fenilpropanoides, resultando este na deposição de compostos fenólicos responsáveis pela estabilização da simbiose (MENSEN et al., 1998; FEUGEY et al., 1999). Em plantas micossimbiontes, a formação destes elicitores, especialmente dos $\mathrm{N}$-acetilglucosamina, garante não somente a associação, mas também sua manutenção e seu crescimento no decorrer do tempo (SALZER et al., 1996). Burgess et al. (1995) e Lagrande et al. (2001) demonstraram a síntese destes polipeptídeos durante a simbiose ectomicorrízica em Eucalyptus grandis. Desta forma, possivelmente a utilização do óleo essencial de Eucalyptus grandis atue de forma similar à que ocorre na natureza, como promotor do crescimento miceliano de isolados ectomicorrízicos in vitro.

\section{CONCLUSÕES}

O estímulo ao crescimento fúngico devido à adição do óleo essencial de Eucalyptus grandis ao meio de cultura MNM líquido apresenta respostas de dose-efeito, dependendo da concentração do óleo essencial e do isolado ectomicorrízico utilizado;

O óleo essencial de Eucalyptus grandis utilizado em meio de cultura líquido apresenta eficiência para o aumento na massa de micélio fúngico dos isolados ectomicorrízicos Pisolithus microcarpus (UFSC Pt 116), Pisolithus sp. (UFSC Pt 24), Chondrogaster angustiporus (isolado UFSC Ch 163), Scleroderma citrinum (isolado UFSC Sc 124) e Suillus sp. (isolados UFSM RA 2.2 e UFSM RA 2.8);

O óleo essencial de Eucalyptus grandis, em concentrações acima de $40 \mu \mathrm{L} \mathrm{L}^{-1}$, atua como supressor da atividade fúngica, limitando o crescimento miceliano in vitro.

\section{REFERÊNCIAS BIBLIOGRÁFICAS}

ATANDA, O. O. et al. The potential of some species essential oils in the control of A. parasiticus CFR 223 and aflatoxin production. Food Control, Reading, v. 18, n. 5, p. 601-607, May 2007.

BÂ, A. M. et al. Management of ectomycorrhizal symbionts associated to useful exotic tree species to improve reforestation performances in tropical Africa. Annals of Forest Science, Champenoux, v. 67, n. 3, p. 298-307, May 2010.

BAKKALI, F. et al. Biological effects of essential oils - A review. Food and Chemical Toxicology, Richmond, v. 46, n. 2, p. 446-475, Feb. 2008.

BAPTISTA, M. J. et al. Produção de compostos fenólicos durante a infecção ectomicorrízica por dois isolados de Pisolithus tinctorius em Eucalyptus urophylla in vitro. Revista brasileira de Botânica, São Paulo, v. 22, n. 2, p. 309-315, out. 1999.

BARANSKA, M. et al. Vibrational spectroscopic studies to acquire a quality control method of Eucalyptus essential oils. Biopolymers, Hoboken, v. 78, n. 5, p. 237-248, Apr. 2005.

BRIMECOMBE, M. J.; LEIJ, F. A. de; LYNCH, J. M. The effect of root exudates on rhizosphere microbial populations. In: PINTON, R.; VARANINI, Z.; NANNIPIERI, P. The rhizosphere: biochemistry and organic substances at the soil-plant interface. New York: Marcel Dekker, 2001. 424 p.

BRUNNER, I. Ectomycorrhizas: their role in forest ecosystems under the impact of acidifying pollutants. 
Perspectives in Plant Ecology, Evolution and Systematics, Zürich, v. 4, n. 1, p. 13-27, June 2001. BURGESS, T. et al. Effect of fungal-isolate aggressivity on the biosynthesis of symbiosisrelated polypeptides in differentiating eucalypt ectomycorrhizas. Planta, Bonn, v. 195, n. 3, p. 408417, Jan. 1995.

COURTY, P. E. et al. The role of ectomycorrhizal communities in forest ecosystem processes: New perspectives and emerging concepts. Soil Biology and Biochemistry, Brisbane, v. 42, n. 5, p. 679-698, May 2010.

DEL GIUDICE, L. et al. The microbial community of Vetiver root and its involvement into essential oil biogenesis. Environmental Microbiology, Braunschweig, v. 10, n. 10, p. 2824-2841, Oct. 2008. DENNY, H. J.; WILKINS, D. A. Zinc tolerance in Betula spp. III. Variation in response to zinc among ectomycorrhizal associates. New Phytologist, Lancaster, v. 106, n. 3, p. 535-544, 1987.

ESTANISLAU, A. A. et al. Composição química e atividade antibacteriana dos óleos essenciais de cinco espécies de Eucalyptus cultivadas em Goiás. Revista Brasileira de Farmacognosia, Curitiba, v. 11, n. 2, p. 95-100, jul./dez. 2001.

FABROWSKI, F. J. et al. Investigação da presença de óleo essencial em Eucalyptus smithii R. T. Baker por meio da anatomia de seu lenho e casca. Ciência Florestal, Santa Maria, v. 13, n. 1, p. 95-106, jun. 2003.

FERREIRA, D. F. Sistemas de análise estatística para dados balanceados. Lavras: UFLA/ DEX/SISVAR, 2000. 145 p.

FEUGEY, L. et al. Induced defence responses limit Hartig net formation in ectomycorrhizal birch roots. New Phytologist, Lancaster, v. 144, n. 3, p. 541-547, March 1999.

FORBES, V. E. Is hormesis an evolutionary expectation? Functional Ecology, Amherst, v. 14, n. 1, p. 12-24, Feb. 2000.

GARCÍA, C. et al. Bioxidation of 1,8-cineole by Aspergillus terreus. Journal of Molecular Catalysis B: enzimatic, Delft, v. 59, n. 1-3, p. 171-176, July 2009.

HOBBIE, E. A. Carbon allocation to ectomycorrhizal fungi correlates with belowground allocation in culture studies. Ecology, Davis, v. 87, n. 3, p. 563569, Mar. 2006.

HÖGBERG, M. N.; HÖGBERG, P. Extramatrical ectomycorrhizal mycelium contributes one-third of microbial biomass and produces, together with associated roots, half the dissolved organic carbon in a forest soil. New Phytologist, Lancaster, v. 154, n. 3, p. 791-795, June 2002.

JANDEL SCIENTIFIC. User's manual. California, $1991.280 \mathrm{p}$.

KAINULAINEN, P.; HOLOPAINEN, T; HOLOPAINEN, J. K. Decomposition of secondary compounds from needle litter of Scots pine grown under elevated $\mathrm{CO}_{2}$ and $\mathrm{O}_{3}$. Global Change Biology, Illinois, v. 9, n. 2, p. 295-304, Feb. 2003.

KOIDE, R. T. et al. Interactions between needles of Pinus resinosa and ectomycorrhizal fungi. New Phytologist, Lancaster, v. 140, n. 3, p. 539-547, Nov. 1998.

LAGRANGE, H.; JAY-ALLGMAND, C.; LAPEYRIE, F. Rutin, the phenolglycoside from eucalypt root exudates, stimulates Pisolithus hyphal growth at picomolar concentration. New Phytologist, Lancaster, v. 149, n. 2, p. 349-355, Feb. 2001.

LUDLEY, K. E. et al. Differential response of ectomycorrhizal and saprotrophic fungal mycelium from coniferous forest soils to selected monoterpenes. Soil Biology \& Biochemistry, Brisbane, v. 40, n. 3, p. 669-678, Mar. 2008.

LUDLEY, K. E. et al. Potential for monoterpenes to affect ectomycorrhizal and saprotrophic fungal activity in coniferous forest is revealed by novel experimental system. Soil Biology \& Biochemistry, Brisbane, v. 41, n. 1, p. 117-124, Jan. 2009.

MAFFEI, M. E. Sites of synthesis, biochemistry and functional role of plant volatiles. South African Journal of Botany, Scottsville, In Press, Corrected Proof, Available online 8 Abril 2010.

MARTIN, F. et al. The genome of Laccaria bicolor provides insights into mycorrhizal symbiosis. Nature, London, v. 452, n. 7183 , p. 88-92, Mar. 2008.

MARTINS, M. A.; GONÇALVES, G. F. de; SOARES, A. C. F. Efeito de fungos micorrízicos arbusculares associados a compostos fenólicos, no crescimento de mudas de mamoeiro. Pesquisa Agropecuária Brasileira, Brasília, v. 35, n. 7, p. 1465-1471, jul. 2000.

MARX, D. H. The influence of ectotrophic mycorrhizal fungi on the resistance of pine roots to pathogenic fungi and soil bacteria. I. Antagonism of mycorrhizal fungi to root pathogenic fungi and soil bacteria. Phytopathology, Saint Paul, v. 59, p. 153163, 1969.

MATOS, O. C. de. Substâncias naturais de origem vegetal com actividade biocida: seu uso na protecção das culturas. Lisboa: IIR Portugal, 2004. 14 p.

MEDICE, R. et al. Óleos essenciais no controle da 
ferrugem asiática da soja Phakopsora pachyrhizi Syd. \& P. Syd. Ciência e Agrotecnologia, Lavras, v. 31, n. 1, p. 83-90, jan./fev. 2007.

MENOTTA, M. et al. Headspace solid-phase microextraction with gas chromatography and mass spectrometry in the investigation of volatile organic compounds in an ectomycorrhizae synthesis system. Rapid Communications in Mass Spectrometry, Washington, v. 18, n. 2, p. 206-210, Jan. 2004.

MENSEN, R.; HAGER, A.; SALZER, P. Elicitor - induced changes of wall - bound and secreted peroxidase activities in suspension - cultured spruce (Picea abies) cells are attenuated by auxins. Physiologia Plantarum, Lund, v. 102, n. 4, p. 539546, Apr. 1998.

NEHLS, U. et al. Fungal carbohydrate support in the ectomycorrhizal symbiosis: a review. Plant Biology, Freiburg, v. 12, n. 2, p. 292-301, Mar. 2010.

OLIVEIRA, V. L.; GIACHINI, A. J. Ecologia e aplicação de ectomicorrizas. In: SIQUEIRA, J. O. et al. Inter-relação fertilidade, biologia do solo e nutrição de plantas. UFLA: Lavras, 1999. 818 p.

OLUMA, H. O. A.; GARBA, I. U. Screening of Eucalyptus globulus and Ocimum gratissimum against $P$ ythium aphanidermatum. Nigerian Journal of Plant Protection, v. 21, p. 109-114, 2004.

PERA, J.; PARLADÉ, J. Inoculación controlada con hongos ectomicorrícicos en la producción de planta destinada a repoblaciones forestales: estado actual en España. Investigación Agraria: Sistemas y Recursos Forestales, Madrid, v. 14, n. 3, p. 419-433, 2005.

ROSSI, M. J.; SOUZA, J. A. R.; OLIVEIRA, V. L. Inoculum production of the ectomycorrhizal fungus Pisolithus microcarpus in an airlift bioreactor. Applied Microbiology and Biotechnology, Münster, v. 59, n. 2-3, p. 175-181, July 2002.

SALGADO, S. M. L.; CAMPOS, V. P. Extratos naturais na patogenicidade e reprodução de Meloidogyne exigua em cafeeiro e de Meloidogyne incognita raça 3 em feijoeiro. Nematologia Brasileira, Piracicaba, v. 27, n. 1, p. 41-48, jun. 2003. SALZER, P. et al. Rapid reactions of spruce cells to elicitors released from the ectomycorrhizal fungus Hebeloma crustuliniforme, and inactivation of these elicitors by extracellular spruce cell enzymes. Planta, Bonn, v. 198, n. 1, p. 118-126, Jan. 1996.

SCHAWN-ESTRADA, K. R. F.; STANGARLIN, J. R.; CRUZ, M. E. S. Uso de plantas medicinais no controle de doenças de plantas. In: CONGRESSO BRASILEIRO DE FITOPATOLOGIA, 36., 2003,
Uberlândia. Anais... Uberlândia: SBF, 2003. p. 5456.

SERAFINI, L. A.; CASSEL, E. Produção de óleos essenciais: uma alternativa para a agroindústria nacional. In: SERAFINI, L. A.; BARROS, N. M.; AZEVEDO, J. L. Biotecnologia na agricultura e na agroindústria. Guaíba: Agroindústria, 2001. p. 333-377.

SHRIVASTAVA, G. et al. Plant volatiles-based insect pest management in organic farming. Critical Reviews in Plant Sciences, Apopka, v. 29, n. 2, p. 123-133, Mar. 2010.

SIMIONATTO, E. Estudo dos constituintes químicos de óleos voláteis de plantas medicinais do Rio Grande do Sul: isolamento, determinação e modificação estrutural e atividade biológica. 2004, 193 f. Tese (Doutorado em Química) - Universidade Federal de Santa Maria, Santa Maria, 2004.

SINGH, G.; SINGH, O. P.; MAURYA, S. Chemical and biocidal investigations on essential oils of some indian Curcuma species. Progress in Crystal Growth and Characterization of Materials, v. 45, n. 1-2, p. 75-81, Jan., 2003.

SMITH, S. E.; READ, D. J. Mycorrhizal symbiosis. $3^{\text {rd }}$ ed., San Diego, Academic Press, 2008, 787 p.

SOLIMAN, K. M.; BADEAA, R. I. Effect of oil extracted from some medicinal plants on different mycotoxigenic fungi. Food and Chemical Toxicology, Richmond, v. 40, n. 11, p. 1669-1675, Nov. 2002.

SOUZA, V. C. de et al. Estudos sobre fungos micorrízicos. Revista Brasileira de Engenharia Agrícola e Ambiental, Campina Grande, v. 10, n. 3, p. 612-618, jul./set. 2006.

STEFFEN, R. B.; A NTONIOLLI, Z. I.; STEFFEN, G. P. K. Efeito estimulante do óleo essencial de eucalipto na germinação e no crescimento inicial de mudas de Eucalyptus grandis. Pesquisa Florestal Brasileira, Colombo, v. 30, n. 63, p. 199-206, 2010. TAIZ, L.; ZEIGER, E. Fisiologia Vegetal. 3. ed. Porto Alegre: Artmed, 2004. 719 p.

VITTI, A. M. S.; BRITO, J. O.; Universidade de São Paulo: Escola superior de Agricultura "Luiz de Queiroz". Óleo essencial de Eucalipto. São Paulo, 2003. 26 f. (Documentos, 17).

ZEPPA, S. et al. Tilia platyphyllos Scop.-Tuber brumale Vittad. vs. T. platyphyllos Scop.- T. borchii Vittad. ectomycorrhizal systems: a comparison of structural and functional traits. Plant Physiology and Biochemistry, Paris, v. 43, n. 7, p. 709-716, July 2005. 